\title{
Need for stricter screenings of nursing home workers
}

\section{The need for stricter screenings of nursing home workers}

Elder abuse and neglect is an increasing problem that affects many elderly adults across the United States. It is commonly defined and assessed in a variety of ways. Although neglect should never happen, incidents do occur. Policies have been created to address the forms of abuse that take place. Throughout this analysis, the issue, the historical background, and previous policy responses will be evaluated and encompassed.

\section{Description of the issue necessitating a policy}

By 2030, the youngest of the baby boomer generation will be 65 years old and the oldest will be about $85 .{ }^{1}$ There will be over 71.5 million people reaching the age of 65 and older. Those who are 85 and older are the fastest growing adult population. This doubled from 2004 to 2030, and will double again in $2050 .{ }^{1}$ As age increases, so does service use. These services include nursing homes, adult day cares, assisted living, and use of informal and formal caregivers. ${ }^{2}$ With the increase of the aging population, the exposure to nursing home abuse is likely to increase due to a growing number of residents.

\section{According to Pickering, et al.: ${ }^{3}$}

Elder abuse and neglect $(\mathrm{EA} / \mathrm{N})$ is defined as intentional acts by a person in a trusted relationship with an older adult, which causes harm or risk of harm to the older adult or failure to satisfy the older adult's basic needs. (p. 182)

Physical abuse is when the intention of the abuser is to cause physical injuries and/or pain. Along with physical abuse, there are other forms of abuse including emotional or psychological, sexual, abandonment, neglect, and even financial abuse/exploitation. ${ }^{4}$

Over one million older adults are affected by elder abuse and neglect every year. Every one out of ten older adults fall victim to elder abuse and neglect and more so if the elder suffers with dementia. Women are also said to experience higher rates of elder abuse and neglect, compared to men, especially emotional abuse. ${ }^{3}$ The federal Long-term Care Ombudsman Office reports that $10 \%$ of the complaints received involving nursing homes, relate to allegations involving abuse, neglect, and exploitation. ${ }^{4}$

Elder abuse and neglect are becoming increasingly prevalent due to nursing homes experiencing low staff to patient ratios. ${ }^{2}$ This can be due to challenges in locating an adequate number of qualified staff. In addition, long-term facilities can have a difficult time keeping positions full due to unqualified screenings. Additional causes of elder abuse and neglect include lack of training which incorporates mandated reporting. ${ }^{3}$

Background checks can also be included as a means to address the elder abuse and neglect problem. Background checks typically include: criminal records, education level, drug issues, and professional licensure. Background checks can cost up to $\$ 2,000$, depending on the depth and complexity of the inquiry. ${ }^{5}$ Lower-end
Special Issue - 2018

\author{
Alexis Harney, Kaitlyn Kennon, Ariel Lee, \\ Claire Parsons, Briana Utsey-Bragg, Gracen \\ Williams \\ Western Kentucky University, USA
}

Correspondence: Briana Utsey-Bragg, Western Kentucky University, USA, Email briane@gmail.com

Received: August 16, 2018 | Published: December 31, 2018

background checks also may not be as extensive as those that are more costly or detailed. Therefore, it may be easier for someone who has the potential to emotionally abuse clients to go undetected. Older adults affected by elder abuse and neglect can experience a significant increase in emergency room visits, hospital admission, injuries and other trauma, and even an increase in mortality rates. ${ }^{3}$

\section{Historical background}

\section{Baby boomers}

From the 1940 s to the 1960 s, the population had begun to gradually increase with the birth of the Baby Boomers. With baby boomers composing much of the population, the definition of a traditional family has changed over time. Baby boomers have formed cultures that include single parenting, stepfamilies, heterosexual and homosexual couples who live together, families that have no children, and intergenerational households. However, the baby boomer generation is less likely to have a reliable source of housing or resources when they grow old. This reliable source could include either a spouse or an adult child. This is due to a decrease in childbirth. Soon, baby boomers will cause an increase in the need for long-term care. Given this circumstance, more services for older adults are needed. ${ }^{1}$

President Lyndon B. Johnson expressed his concern about the baby boomer generation early with the 1961 White House Conference on Aging. ${ }^{2}$ The intention of the conference was to brainstorm how to improve the quality of life for older adults. This would include both social and medical services. On July 14th, 1965, President Johnson passed the Older Americans Act [OAA]. Sixteen days later, Medicare and Medicaid were enacted. Medicare programs were created to assist the older population. This would include anyone over the age of 65. At the time, Medicare has two parts: Parts A and B. Part A is hospital insurance whereas part B is medical insurance. With part B, people become more eligible as well as receive more medical benefits. Medicaid however offers insurance to those who have low income as well as meet specific criteria. This criterion would include individuals such as pregnant women, those with disabilities and those who need long-term care. ${ }^{1}$ 


\section{Previous policy responses and current policy Older Americans act}

In 1965, Congress enacted the Older Americans Act. The goal of the Older Americans Act [OAA] was to respond to the concerns about a lack of community social services for older individuals. The main action of the act was to offer grants to states. These grants were to be used towards social services, research projects, and better training in social service fields for older adults. With these grants being used, the Administration on Aging was established through the Department of Health and Human Services, which focused on the concerns of older adults and their well-being on a federal level. ${ }^{6}$

Since the 1960 s, the OAA is periodically reauthorized. As well, as time has progressed, the OAA has been amended multiple times. With each amendment the policy has improved, yet reveals more gaps within each decade. ${ }^{7}$ During the 1960 s, the OAA extended the grants funding programs in place. This led to more accessibility to the resources of the OAA. This increased opportunities for research and added improved training programs for nursing home employees. By 1969 , pilot versions of newer and better social services were being tested to measure if they met the needs for older adults. ${ }^{6}$

By the beginning of the 1970 s, the main concentration of the OAA became nutrition programs. In 1972, two national nutrition programs for the elderly were formed, Elderly Nutrition Program and the Nutrition Services Incentive Program. With these programs, benefits such as nutritious meals, prevention of malnutrition, and community involvement were included. By 1974, the nutritional program had been extended. ${ }^{6}$

In 1973, the Economic Opportunity Act amended employment opportunities concerning community service programs for older adults. These services were changed to be of higher quality for the older adult population. Meaning, Congress authorized the creation of local agencies whose purpose is to plan and coordinate services for older persons and to act as advocates for programs on their behalf. These amendments also created legislative authority for the community service employment program for older Americans. ${ }^{6}$ In 1977, the U.S. Department of Agriculture joined the nutrition program and provided cash payment for food to the states.

In 1984, the Administration on Aging was given responsibilities by the OAA. One of these responsibilities included state funds having more flexibility with services. Other responsibilities included caring for minority populations. Minorities were defined to include patients with Alzheimer's and their families. In 1987, services for the frail elderly were included in social service legislation. ${ }^{6}$

Fiveyears later, Title VII was enacted in the OAA. Under Title VII, Vulnerable Elder Rights Protection Activities was enacted which extended the rights of residents in long-term care facilities. According to Colello and Napili ${ }^{6}$ these rights included residents' rights, full information of their rights, participation in their own care system, privacy and confidentiality, raising concerns and filing complaints, security for possessions, dignity, respect and freedom, and rights to remain in care facility. Along with the Vulnerable Elder Rights Protection Activities under Title VII, Ombudsman Programs were authorized. With these programs, the intentions are to prevent any forms of elder abuse, neglect, and exploitation. This is done by promoting programs that enlighten the rights of elders as well as legal assistance development, forms of outreach, counseling programs for older adults and insurance assistance for programs that provide public benefits. The programs identified three main forms of elder abuse: physical, psychological, and financial. ${ }^{6}$

\section{Elder justice act}

Under the Affordable Care Act of 2010, the Elder Justice Act was enacted. Prior to the Elder Justice Act, services for older adults were not as supported due to a lack of reporting of elder abuse and ignorance towards the subject of elder abuse. But with the Elder Justice Act being enacted, initiatives were put together to protect elders and their rights on a federal level. A few of these initiatives included: the creation of more support and federal funding for state Adult Protective Services (APS) and dedicated resources at the Health and Human Services for collection of data and other research related to APS; increasing resources for the Long-term Care Ombudsman Program; requirements for mandated reporting; creation of penalties for facilities that retaliate against employees; and establishment of a nationwide program for background checks concerning employees with direct access to patients. ${ }^{1}$

\section{Current policies in place}

In the state of Kentucky, a committee has been put together to prevent elder abuse and spread awareness of abuse in nursing homes. In 2010, the chapter KRS 209 under Title XVII was created. The chapter has a total of 21 sections. A few of these sections include reporting abuse, protective services, and staffing requirements. In relation to the Elder Justice Act, KRS 209 is a chapter that meets the standard of its initiatives as well as meeting the standards of the OAA. It states that a nursing home facility must provide protection for older Americans who are suffering from abuse, neglect or exploitation. KRS 209.010 also states:

To provide that any person who becomes aware of such cases shall report them to a representative of the cabinet, thereby causing the protective services of the state to be brought to bear in an effort to protect the health and welfare of these adults in need of protective services and to prevent, neglect, or exploitation.

This asserts there will be definite consequences for those who fail to report what they perceive to be an abusive situation. This also includes long-term nursing facilities.

In 2012, KRS 216.533 was amended. With KRS 216.533, criminal background checks were enacted related to the employment requirements of nursing homes. Anyone that has a record that is not erased fails to eligibility for employment. In regard to KRS 209, KRS 216.533 extends the efforts to prevent elder abuse, especially within a nursing home facility. KRS 216.533 defines long term care facilities as family-care homes, personal care homes, and skilled-nursing facilities.

\section{Funding mechanism}

The Older Americans Act [OAA] was passed in 1965 due to concern about the severe lack of social services for older adults. ${ }^{8}$ The OAA was put into place as a permanent policy to be renewed every three years by the federal government. The policies that were influenced through the OAA were created with the same intent. This led to a distinct line of funding from the federal to state level. The OAA not only influenced Statute 216.533, it funds the statute, too. The OAA funds many services related to elder care. Some of these include legal services, elder abuse prevention, and caregiver support. ${ }^{7}$ 
Through the OAA, the Administration on Aging and the current aging services network were created. Part of this aging network, the Area Agencies on Aging [AAA], obtains funding through what is allocated to the OAA. The amount of funding given is based on the proportion of residents in the state that are 60years and older. Over 600 AAAs gains funding from the federal level. It is their responsibility to distribute funds to programs provided under Title VII of the OAA. The programs funded through the local AAAs encompass and ensure the rights of older adults found in the OAA and sequentially in KRS 209.

An example of one of the most successful programs funded through the OAA, the Long-term care Ombudsman program, investigates and resolves complaints made by, or on behalf of, nursing home residents. Savings in Medicare and Medicaid led to the reasoning behind the current dedication to funding such extensive elder protection. Even though research showed that there is a direct connection between increased need for expensive care, such as nursing homes and elder care, funding the OAA to compensate for possible risks led to potential savings within Medicare and Medicaid.

Funding can also come to long-term care facilities through Civil Money Penalty [CMP] Funds. The creation of these funds stem from both the Social Security Act and the Affordable Care Act. Nursing homes are eligible for using this grant if they are not receiving other grants from federal or state resources. The long-term care Ombudsman programs may also use the money provided from this grant. The money must be used to benefit and protect long-term care facility residents and residents of other qualified facilities. However, the funds from CMP were not allocated to fund training for the Ombudsman or staffing of long-term care facilities. ${ }^{9}$

\section{Coordination and criteria}

According to both Chapters 209 and 216 of the Kentucky Revised Statutes, the Cabinet of Health and Family Services directed how the actions of both were carried out. The state-level screenings that occur on behalf of KRS 216.533, and the related chapter KRS 209, are regulated through the National Background Check Program [NBCP]. The NBCP gives a grant to Kentucky through the center of Medicare and Medicaid. The grant goes to fund a state and national fingerprint check of potential employees. The background check looks at the criminal history through the Kentucky State Police and the Federal Bureau of Investigations. The disqualifying offenses for employment include neglect and abuse within long-term care facilities listed under KRS 209. Through Kentucky, the screening program bears the name KARES (Kentucky Applicant Registry and Employment Screening) and does both pre-employment screening and intermittent screenings of the same kind after employment. KARES results indicate a division between potential abusers and qualified workers through the process outlined in KRS 216.533 and KRS 209, which serves as a formal indication of policy effectiveness. ${ }^{9}$

Other criteria for success have been outlined under the supervision of the previous governor of Kentucky, Steve Beshear. After a newspaper published an article questioning the process Kentucky uses for investigating and prosecuting nursing home abuse and neglect, Beshear gathered a group of politicians and advocacy groups. There was a general discussion about how the state could be more effective in eradicating elder abuse in institutional settings. The Attorney General at the time mentioned that with his focus on stopping abuse and neglect, he had filed more abuse and neglect cases than any in office before him. He took part in the discussion in hope that Governor Beshear would make the efforts to stop abuse and neglect more efficient by helping in filing more cases. While this is not a standard of efficiency, the Attorney General noted it as one. ${ }^{10}$

Discussions also compared components of Kentucky's long-term care to federal standards. Kentucky was found to have many of these same standards represented in the preventative protection services in place. These standards include mandatory reporting, multidisciplinary investigative teams, dedicated staffing, forensically trained employees, post-event review panels, and public awareness and education. Based on the priorities different government groups and advocacy groups presented, all entities present agreed on 20 recommendations to be put into place to ensure the current policies on elder abuse were effective. Many of the recommendations outlined specific ways employees could be trained or arranged to make the execution of the policies more efficient- such as improving notifications or increasing training. It was also decided that the statements of the deficiencies in how the policy had been executed would be published to the public. ${ }^{10}$

\section{Policy analysis}

The Older Americans Act of 1965 was created to assist older adults with "maintaining independence and dignity". ${ }^{11}$ One form of this is protection from elder abuse. ${ }^{11}$ Approximately 6.3million older adults need long-term care. By 2050, the number of people in need of longterm care is expected to double, which is attributed to the increase in the aging population. ${ }^{1}$ Under KRS 216.2925, the Cabinet for Health and Family Services are required to coordinate quarterly surveys that showcase the statistics gathered from reports concerning quality of care in long-term facilities. The main facilities highlighted in the reports were more medically based such as hospitals and ambulatory services. Services included outpatient centers, surgical centers, and dialysis centers. Long-term care facilities such as nursing homes were classified simply as "other providers" and not accurately represented. The surveys that were conducted focused on demographics and measured payment methods of the residents in long-term care facilities. The issue with how the surveys are conducted is that surveys are passed out to the administration of these facilities by the Cabinet. With no guarantee that the residents can comprehend questions and complete the survey, there are major discrepancies in the reliability in the results of these surveys.

It is a fundamental human right to live life with a sense of security. To date, Congress has not appropriated any money for the implementation of the Elder Justice Act. ${ }^{12}$ Additionally, with each iteration of Congress the Elder Justice Act undergoes revision. ${ }^{13}$ This sometimes results in key components not being funded, such as data collection and grants, which would help in all aspects of prevention of elder abuse. ${ }^{14}$ The small number of reports for elder abuse happens on both the state and national levels. This is worrisome since it does highlight the many gaps in the policy that is in place. The OAA and Elder Justice Act may have been put into place to try to help maintain an acceptable quality of life, but it is very clear that it falls short.

The Patient Safety and Abuse Prevention Act (PSAPA), was implemented in 2010 as a provision of the ACA alongside the Elder Justice Act. It expanded a pilot program that created a national criminal background check. ${ }^{16}$ It compared abuse and neglect registries from accessing information from state police records. The reports that come from state police records will then be compared to the results from the FBI's national database of criminal records. While 
this can seem theoretically sound, there are flaws in the system that can allow those with a criminal record to evade detection and secure employment at long-term care facilities. One such flaw is that this is an optional state program. The following provider-types are subject to the nationwide background check program in participating states: skilled nursing facilities, nursing facilities, home health agencies, hospice providers, personal care providers, adult day care providers, certain residential care, assisted living providers and intermediate care facilities for those with mental disabilities. ${ }^{16}$ However, though there is federal funding related to the application of this, it is not required for states to be involved.

Like any other policy, there are funding difficulties in execution. A survey conducted in 2011 across 30 states reported that the Adult Protective Service [APS] had faced budget cuts of an average of $14 \%$, while they face an increase of elder abuse reports on average of $24 \% .{ }^{14}$ This discrepancy between funding and the issue of elder abuse highlights just how much work and funding is still needed. Costeffectiveness is usually a priority when procedures like screenings are being reviewed. Funding for education and ongoing training is expensive, which could lead agencies to opt out of participation. However, without additional education and training, long-term care facilities may not be adequately accounting for prevention strategies for their residents. This can result in a potential increase of incidences of elder abuse. ${ }^{14}$

Another way that these residential care facilities attempt to bring down expenses is by favoring inexpensive background checks. These lower quality background checks have higher error rates, therefore, individuals with substantiated abuse and/or criminal records can become employed by long-term care facilities. This can increase the exposure of harmful individuals to the older adult population who would otherwise benefit from these institutions. ${ }^{9}$

From the Elder Justice Act there are a number of gaps in funding, education, and research. ${ }^{14}$ As discussed previously, funding is a key component which impacts policy because it contributes to the gaps. With the limited funding, there has not been enough data collected to evaluate how best to educate and train professionals who work with this vulnerable population. If there were studies over another issue with the lack of research is that both protective and risk factors of elder abuse are not clearly defined. Even from the OAA, there are still problems with this program addressing issues concerning racial minorities, the poor, and the lonely; as they are less likely to seek professional help. Due to this, they are the population most at risk to suffer from elder abuse. ${ }^{2}$

State and Federal policy does not clearly define the parameters of investigations of screenings for long-term care facilities. Multiple programs require screenings; however, how they go about conducting them can vary. This can skew analysis of these screenings as they are unlikely to be similar to each other. With so much variation there is no valid or reliable means of screening to lessen the likelihood of perpetrators being employed by long-term care facilities (KRS 216.533). Even if a person commits elder abuse, there are no set guidelines for punishment. Under KRS 209.180, the persecution of adult abuse, neglect, and exploitation can only be addressed by attorneys if the personnel are available. This is problematic because guilty parties can avoid serious punishments. This negatively affects the counties that do not have an attorney trained to handle cases such as this elder abuse. The only interview this section required is the interview of the allegedly abused victim. An issue arises from this if the victim does not have the capability to come forth about any harmful situations they may be facing.

How often screenings should be administered is not clarified. A person may have good qualifications, but as they struggle with a highly stressful work environment, over time they may become susceptible to the use of maladaptive behaviors. Therefore, it is crucial to have a more regular screening system in place. This decreases the potential of perpetrators of elder abuse in long-term care facilities. Another important facet of regulated screenings would be having an allencompassing screening. A screening that focuses only on physical abuse will not detect signs of emotional, sexual, or exploitation of elders.

\section{Conclusion}

The OAA did not originally make provisions for the impoverished, minorities, or isolated elders. KRS 209, the Adult Protection Act of Kentucky, also failed to implement specific provisions that assist the marginalized elder population. ${ }^{2}$ Unintentionally this became a consequence of the lack of legislation. The OAA, and state legislations such as KRS 209, failed to adequately respond to the steady rise in elder abuse. Since the baby boomer population is aging, it is expected that reported elder abuse cases would also steadily increase. The National Hispanic Council of Aging illustrates this consequence by stating that, "The U.S needs to modernize the OAA by adequately funding its work and making it responsive to the needs of diverse older adults". ${ }^{17}$ While the OAA and KRS 209 failed to serve these specific populations, the policy did benefit elders as a whole, which is the target population. This is evident through the string of legislation that began with the OAA and continues to the state level. ${ }^{18,19}$

Currently, the status of the OAA will not change until the year 2019 when it is reauthorized. ${ }^{8}$ It can be assumed that since the policy will not be assessed again until 2019 , there will not be any provisions made to accommodate for elder abuse in the near future, such as improved long-term facility staff screenings. Since the OAA has a direct effect on state policy, KRS 209 will reflect the lack of assessment, too. Outside of KRS 209, KRS 216.533 authorizes criminal background checks but no other screenings. Criminal background checks assume that the perpetrators have been previously convicted for committing elder abuse. However, this is not always the case. This is why KRS 216.533 needs to be amended and incorporate better screening procedures for long-term facility staff.

\section{Acknowledgements}

None.

\section{Conflict of interest}

Author declares that there is no conflict of interest.

\section{References}

1. Wacker RR, Roberto KA. Community resources for older adults: Programs and services in an era of change. 4th ed. Thousand Oaks, CA: Sage Publications; 2014.

2. Varner K. Growth of the Older Population [PowerPoint Slides]. 2017.

3. Pickering C, Ridenour K, Salaysay Z. Best practices for the identification of elder abuse and neglect in home health. Home Healthc Now. 2016;34(4):182-188. 
4. Bern-Klug M, Sabri B. Nursing home social service directors and elder abuse staff training. J Gerontol Soc Work. 2012;55(1):5-20.

5. Shipman D, Hooten J. Staff background checks: Safeguarding vulnerable adults. Nursing Older People. 2009;21(4):23-26.

6. Colello KJ, Napili A. Older Americans Act: Background and overview. Congressional Research Service. 2016:1-19.

7. National Committee to Preserve Social Security and Medicare. Older Americans Act. 2016.

8. Administration for Community Living. Older Americans Act. 2017.

9. Kentucky Cabinet of Health and Human Services. Office of Inspector General. KARES. 2017.

10. U.S. Department of Health and Family Services Cabinet. Gov Beshear directs immediate implementation of recommendations for investigating nursing home neglect, abuse. 2010.

11. Neale AV, Hwalek MA, Goodrich CS, et al. The Illinois elder abuse system: Program description and administrative findings. The Gerontologist. 1996;36(4):502-511.
12. National Adult Protective Services Association (NAPSA). Elder Justice Act. 2012.

13. Lindberg BW, Sabatino CP, Blancato RB. Bringing national action to a national disgrace: The history of the Elder Justice Act. NAELA Journal. 2011;7(1):105-118.

14. Dong $X$, Simon MA. Enhancing national policy and programs to address elder abuse. JAMA. 2011;305(23):2460-2461.

15. White ML. What is the Patient Safety and Abuse Prevention Act. 2010.

16. Rubinger HS, Grozine JT. Client Alert. Arnall Golden Gregory. 2010.

17. National Hispanic Council on Aging (NHCOA). The future of the Older Americans Act (OAA). 2016.

18. Family Caregiver Alliance. National Center on Caregiving. Selected long-term care statistics. 2015.

19. Kentucky Cabinet of Health and Human Services. Office of Inspector General. Civil money penalty (CMP) funds. 2016. 